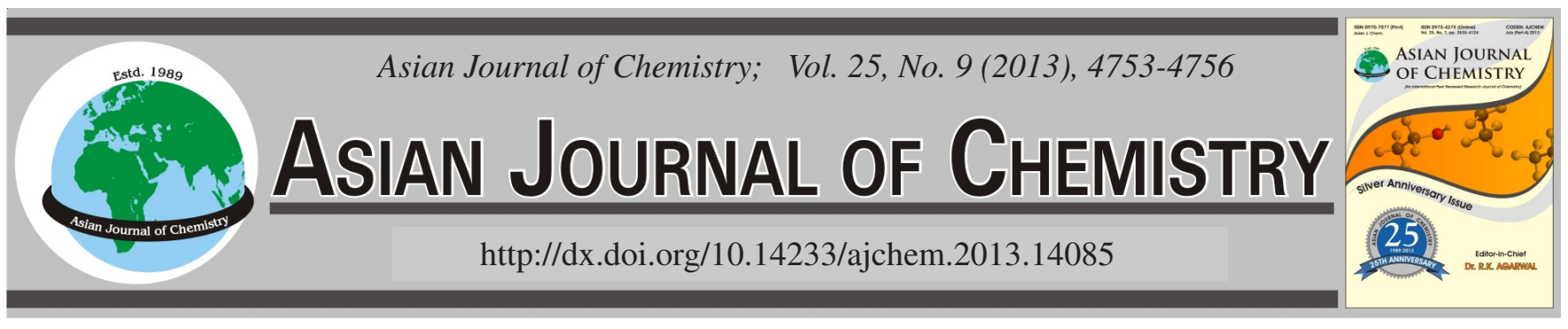

\title{
Solvent Extraction Separation of Titanium(IV) and Iron(III) from Acid Chloride Solutions by Trioctylphosphine Oxide
}

\begin{abstract}
X.H. MAO ${ }^{1,2, *}$ and D.J. $\mathrm{LiU}^{1}$
${ }^{1}$ Sichuan University, Chengdu 610065, Sichuan Province, P.R. China

${ }^{2}$ Panzhihua University, Panzhihua 617000, Sichuan Province, P.R. China

*Corresponding author: E-mail: chdmaoxh@sina.com

(Received: 22 May 2012;

Accepted: 4 March 2013)

AJC-13063

The solvent extraction of calcium(II), magnesium(II), aluminum(III), titanium(IV) and iron(III) from acidic chloride solutions by trioctyl phosphine oxide (TOPO) in kerosene has been investigated. The solvent extraction results demonstrate that the dissolved titanium and iron is present as $\mathrm{TiCl}_{4} \cdot 2 \mathrm{TOPO}$ and $\mathrm{HFeCl}_{4} \cdot \mathrm{TOPO}$. Extraction of titanium(IV) and iron(III) increase with increased hydrochloric acid concentration in the aqueous phase. On the other hand, aluminum(III), calcium(II) and magnesium(II) are not extracted under these experimental conditions. IR spectral studies of the extracted complexes were further used to clarify the nature of the extracted complexes. Titanium(IV and iron(III) can be selectively recovered from the loaded organic phase by controlling the acidity of the stripping agent. The loading capacity of the TOPO system has been evaluated and the potential for the separation and recovery of titanium(IV) and iron(III) from acid chloride liquors has been assessed through extraction and stripping isotherms.

Key Words: TOPO, Solvent extraction, Separation, Titanium, Iron.
\end{abstract}

\section{INTRODUCTION}

Nowadays, solvent extraction is widely used for the recovery of valuable metals from industrial streams. The investigation on the solvent extraction of titanium mainly focused on acid leaching-solvent extraction technique of production of $\mathrm{TiO}_{2}{ }^{1-3}$ and the treatment of wasted chloride liquors generated through 'chloride process' to manufacture white pigment $\mathrm{TiO}_{2}{ }^{4}$. A survey of the literature shows that either acidic organophosphorus extractants ${ }^{5}\left(\mathrm{D}_{2} \mathrm{EHPA}^{6}\right.$, EHEHPA $^{7}$, HBTMPP $^{8}$ ) or neutral organophosphorus extractants $\left(\mathrm{TBP}^{9,10}\right.$, Cyanex $\left.923^{11}\right)$ have been used for the selective recovery of titanium from leach liquors. The solvent extraction of iron has been widely investigated. Among these reports Karimi and Gheadi ${ }^{12}$ studied the extraction behaviour of iron from aluminium sulphate leach solution using acetylacetone-chloroform as extractants.

The main disadvantage with acidic organophosphorus extractants is the slow kinetics of extraction (40-120 min). Among neutral organophosphorus extractants TBP, Cyanex 923 and TOPO have been investigated for the extraction of titanium(IV). Allal et al. ${ }^{13}$ studied the extraction behaviour of titanium(IV) from hydrochloric acid and calcium chloride solutions using TBP, TOPO and decanol as extractants. However these authors have not disclosed results concerning the stripping behaviour and the extraction of other associated metal ions. Hence in the present study, the authors have carried out an investigation on the solvent extraction of calcium(II), magnesium(II), aluminum(III), titanium(IV) and iron(III) from acidic chloride solutions by trioctylphosphine oxide in kerosene to realize the separation of several metal ions from acidic chloride solutions.

\section{EXPERIMENTAL}

Titanium(IV) and iron(III) solutions were prepared from $\mathrm{TiCl}_{4}$ and $\mathrm{FeCl}_{3}$ by diluting to the required concentration with hydrochloric acid. Other metal ion solutions were prepared by dissolving their salts in hydrochloric acid and diluting to the required concentration with distilled water. Trioctyl phosphine oxide (TOPO) was supplied by Tokyo Chemical Industry Co., Japan with an average $\mathrm{mol} \mathrm{wt}=386.63$. All other chemicals used were of analytical reagent grade.

A 721 UV-visible spectrophotometer and a Nicolet 6700 IR spectrophotometer were employed.

Extraction and analytical procedures: Solvent extraction and stripping experiments were carried out by shaking required volumes of organic and aqueous phases at an O/A phase radio of 1 for $10 \mathrm{~min}$ at $298 \pm 1 \mathrm{~K}$. After phase separation, the concentration of the specific metal ion remaining in the aqueous phase was determined by standard procedures. Thus, 
titanium(IV), iron(III), aluminum(III), magnesium(II) and calcium(II) were analyzed spectrophotometrically using, respectively hydrogen peroxide, 1,10-phenanthroline, Eriochrome Cyanine R, Eriochrome black-T and ACBK. The concentration of the metal ion in the organic phase was attained by mass balance.

The metal-TOPO complexes were prepared using solvent extraction by repeated contact of fresh portions of 0.0175 mol dm ${ }^{-3}$ metal solutions with $0.035 \mathrm{~mol} \mathrm{dm}^{-3}$ TOPO in kerosene.

\section{RESULTS AND DISCUSSION}

Extraction equilibria: The extraction behaviour of calcium(II), magnesium(II), aluminum(III), titanium(IV) and iron(III) in chloride liquors was investigated as a function of hydrochloric acid concentration (0.5-11.5 $\left.\mathrm{mol} \mathrm{dm}^{-3}\right)$ using TOPO in kerosene as extractant (Fig. 1). Extractions of titanium(IV) and iron(III) were found to increase with increased hydrochloric acid concentration in the aqueous phase. On the other hand, calcium(II), magnesium(II) and aluminum(III) were not extracted under these experimental conditions.

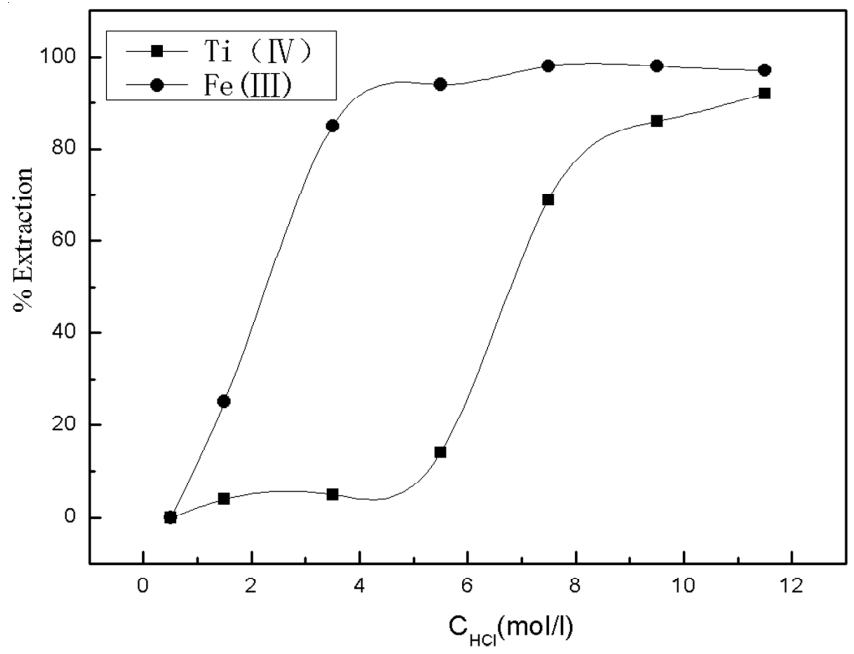

Fig. 1. Extraction behaviour of titanium(IV) $\left(0.0175 \mathrm{~mol} \mathrm{dm}^{-3}\right)$ and iron(III) $\left(0.0175 \mathrm{~mol} \mathrm{dm}^{-3}\right)$ from hydrochloric acid solutions using TOPO $\left(0.035 \mathrm{~mol} \mathrm{dm}^{-3}\right)$ in kerosene

To explore further the extraction mechanism the following investigation was studied.

The effect of chloride ion concentration $\left(6-10 \mathrm{~mol} \mathrm{dm}^{-3}\right)$ on the extraction of titanium(IV) with $0.035 \mathrm{~mol} \mathrm{dm}^{-3}$ TOPO in kerosene was investigated at a given hydrogen ion concentration $\left(6 \mathrm{~mol} \mathrm{dm}^{-3}\right)$ using $\mathrm{HCl}+\mathrm{CaCl}_{2}$ mixtures (Fig. 2). It is clear from the result that the extraction of titanium(IV) increases with increase in chloride concentration in the aqueous phase. The $\log \mathrm{D}$ versus $\log \left[\mathrm{Cl}^{-}\right]$plots gave slopes of 4 in the case of titanium(IV), indicating the involvement of four chloride ions in the extracted complex of titanium(IV).

The effect of TOPO concentration on the extraction of titanium(IV) has been studied by maintaining constant concentrations of titanium(IV) $\left(0.0175 \mathrm{~mol} \mathrm{dm}^{-3}\right)$ and hydrochloric acid $\left(7.5 \mathrm{~mol} \mathrm{dm}^{-3}\right)$ (Fig. 3) and the result shows that the extraction of titanium(IV) increases with increased extractant

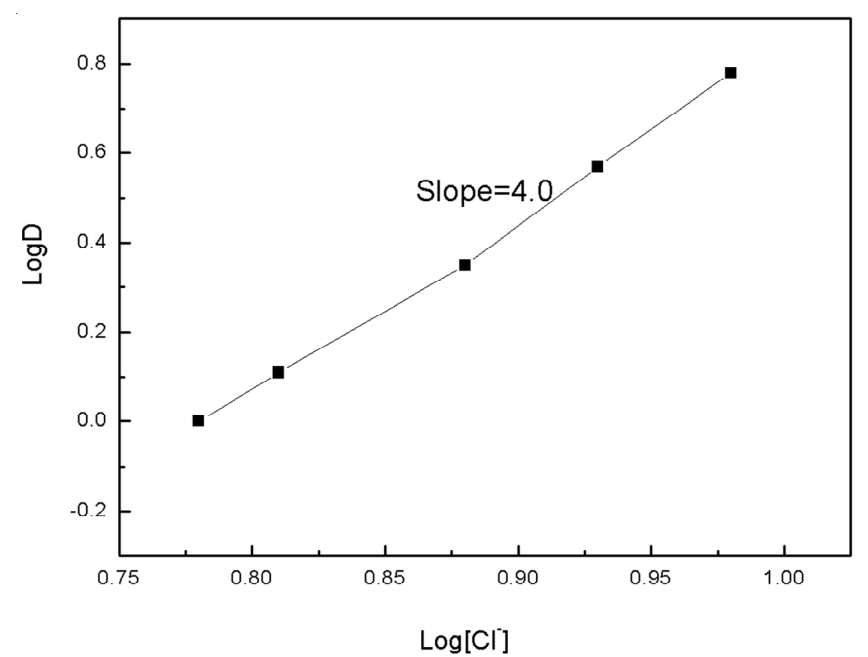

Fig. 2. Effect of chloride ion concentration on the extraction of titanium(IV) $\left(0.0175 \mathrm{~mol} \mathrm{dm}^{-3}\right)$ at constant hydrogen ion concentration $(6 \mathrm{~mol}$ $\left.\mathrm{dm}^{-3}\right),[$ TOPO $]=0.035 \mathrm{~mol} \mathrm{dm}^{-3}$

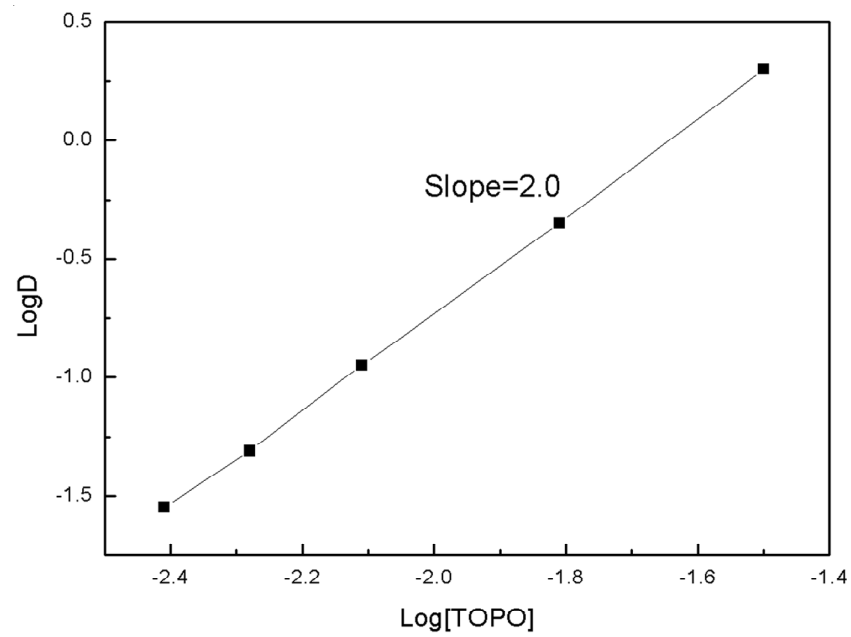

Fig. 3. Effect of TOPO concentration on the extraction of titanium(IV) $\left(0.0175 \mathrm{~mol} \mathrm{dm}^{-3}\right)$ from $7.5 \mathrm{~mol} \mathrm{dm}{ }^{-3}$ hydrochloric acid solution

concentration. From the slope of $\log \mathrm{D}$ versus $\log$ [TOPO], it can be inferred that two molecules of TOPO are involved in the extracted complex of titanium(IV).

The extraction behaviour of titanium(IV) with $0.035 \mathrm{~mol}$ $\mathrm{dm}^{-3}$ TOPO in kerosene was investigated as a function of hydrogen ion concentration $\left(6-10 \mathrm{~mol} \mathrm{dm}^{-3}\right)$ at a given chloride ion concentration $\left(10 \mathrm{~mol} \mathrm{dm}^{-3}\right)$ using $\mathrm{HCl}+\mathrm{CaCl}_{2}$ mixtures (Fig. 4). The result shows that the extraction of titanium(IV) was independent of hydrogen ion concentration in the range from $6-10 \mathrm{~mol} \mathrm{dm}^{-3}$.

Based on the preceding studies, the extraction equilibria of titanium(IV) with TOPO in kerosene can be expressed as:

$$
\mathrm{Ti}^{4+}{ }_{\text {aq }}+4 \mathrm{Cl}^{-} \text {aq }+2 \mathrm{TOPO}_{\text {org }}=\mathrm{TiCl}_{4} \cdot 2 \mathrm{TOPO}_{\text {org }}
$$

The result is consistent with former report ${ }^{13}$. Earlier results ${ }^{14}$ showed that iron(III) was extracted from hydrochloric acid solutions with TOPO in kerosene as:

$$
\mathrm{H}^{+}{ }_{\text {aq }}+\mathrm{FeCl}_{4 \mathrm{aq}}^{-}+\mathrm{TOPO}_{\text {org }}=\mathrm{HFeCl}_{4} \cdot \mathrm{TOPO}_{\text {org }}
$$

Effect of phase contact time: Titanium(IV) and iron (III) were contacted with $0.035 \mathrm{~mol} \mathrm{dm}{ }^{-3}$ TOPO in kerosene for a period of 1-30 min. Quantitative extraction of titanium(IV) 


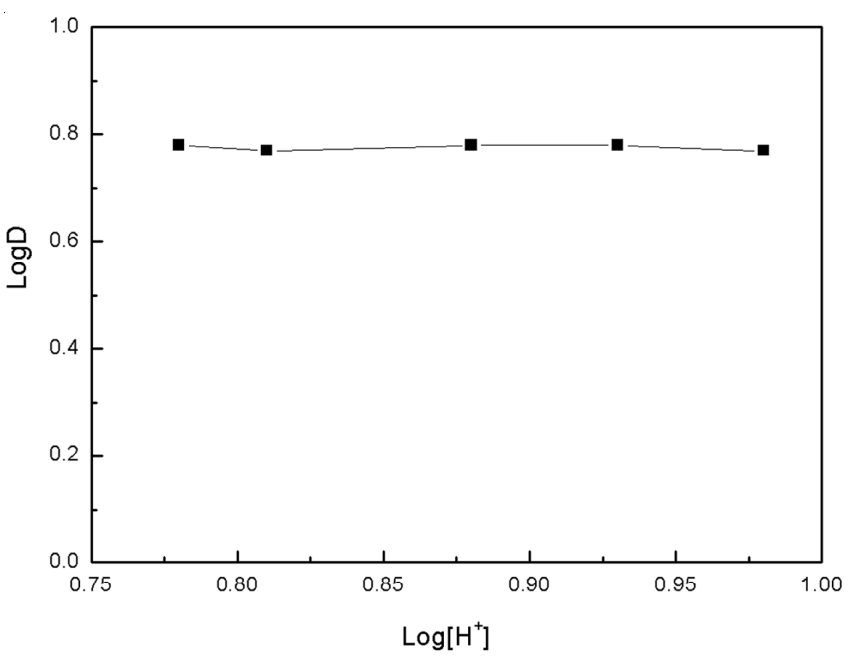

Fig. 4. Effect of $\mathrm{H}^{+}$concentration on the extraction of titanium(IV) $(0.0175$ mol $\left.\mathrm{dm}^{-3}\right)$ at constant chloride ion concentration $\left(10 \mathrm{~mol} \mathrm{dm}^{-3}\right)$, [TOPO $]=0.035 \mathrm{~mol} \mathrm{dm}^{-3}$

and iron(III) by TOPO was found within $5 \mathrm{~min}$. There was no adverse effect on the extraction yield up to $0.5 \mathrm{~h}$ (Fig. 5). From the result it was found that the extraction of titanium(IV) and iron(III) by TOPO from hydrochloric acid solutions are quicker processes than that by acidic organophosphorus extractants.

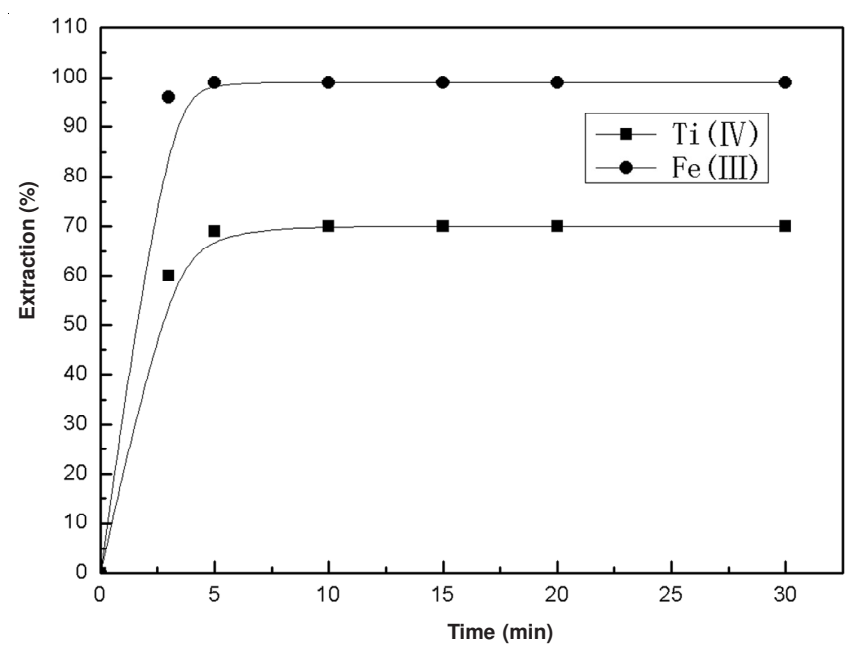

Fig. 5. Dependence of extraction rate on contact time. [Ti] $=0.0175 \mathrm{~mol}$ $\mathrm{dm}^{-3},\left[\mathrm{Fe}^{3+}\right]=0.0175 \mathrm{~mol} \mathrm{dm}^{-3},[\mathrm{TOPO}]=0.035 \mathrm{~mol} \mathrm{dm}^{-3},[\mathrm{HCl}]=$ $7.5 \mathrm{~mol} \mathrm{dm}^{-3}$

IR spectra of the extracted complexes of titanium(IV) and iron(III): The IR spectra of the extracted complexes showed that the stretching frequency of $\mathrm{P}=\mathrm{O}$ was shifted from $1169 \mathrm{~cm}^{-1}$ in TOPO to $1064 \mathrm{~cm}^{-1}$ in $\mathrm{TiCl}_{4} \cdot 2 \mathrm{TOPO}$ and 1080 $\mathrm{cm}^{-1}$ in $\mathrm{HFeCl}_{4} \cdot$ TOPO. These changes confirm that the extracted complexes are formed via coordination of the oxygen lone pair in the $\mathrm{P}=\mathrm{O}$ group of $\mathrm{TOPO}$ to the metal ion.

Loading capacity of TOPO by titanium(IV) and iron(III): Aliquots of $10 \mathrm{~cm}^{3}$ of $0.035 \mathrm{~mol} \mathrm{dm}^{-3} \mathrm{TOPO}$ in kerosene were repeatedly extracted at $298.15 \pm 1 \mathrm{~K}$ for $10 \mathrm{~min}$ with equal volumes of aqueous phases containing $0.0175 \mathrm{~mol}$ $\mathrm{dm}^{-3}$ titanium(IV) or $0.0175 \mathrm{~mol} \mathrm{dm}{ }^{-3}$ iron(III) in $7.5 \mathrm{~mol} \mathrm{dm}^{-3}$ hydrochloric acid. The aqueous phases were analyzed after each stage of extraction and the cumulative metal content extracted into the organic phase was calculated. It is clear that the maximum loading capacity for iron(III) is $7.70 \mathrm{~g} / 100 \mathrm{~g}$ TOPO, whereas the loading capacity for titanium(IV) is 4.60 $\mathrm{g} / 100 \mathrm{~g}$ TOPO.

Extraction isotherms: Extraction isotherms have been generated for a typical feed solution containing $0.03 \mathrm{~mol} \mathrm{dm}^{-3}$ titanium(IV) or $0.03 \mathrm{~mol} \mathrm{dm}^{-3}$ iron(III) in $7.5 \mathrm{~mol} \mathrm{dm}^{-3}$ hydrochloric acid using $0.044 \mathrm{~mol} \mathrm{dm}^{-3}$ of TOPO and $10 \%$ decanol in kerosene (Figs. 6 and 7). The McCabe-Thiele plot for a feed solution containing $0.03 \mathrm{~mol} \mathrm{dm}^{-3}$ titanium(IV) shows almost quantitative extraction was possible in three-stage countercurrent extraction at a 1:2 aq:org phase ratio. Similarly, the McCabe-Thiele plot for a feed solution containing 0.03 mol dm${ }^{-3}$ iron(III) shows that almost quantitative extraction was possible in one stage at a 1:2 aq:org phase ratio.

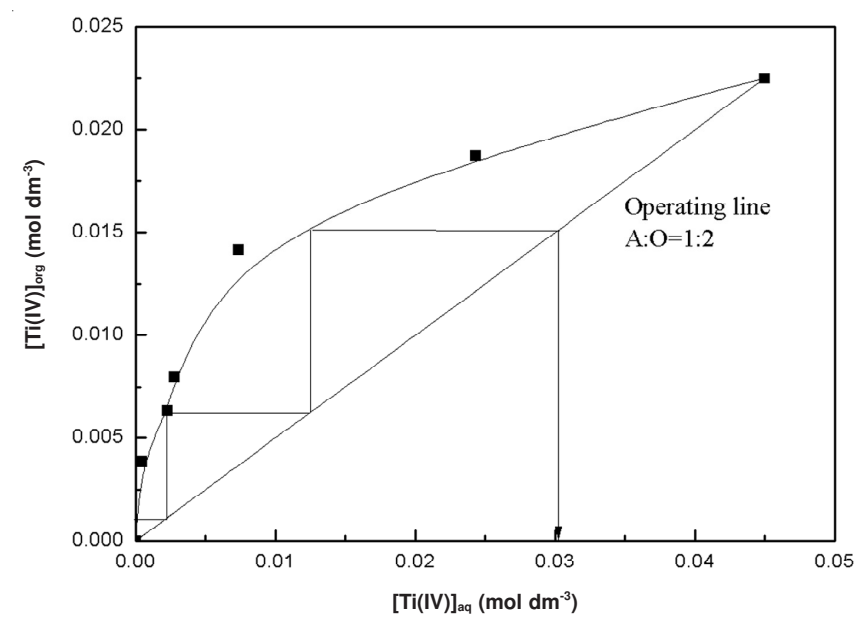

Fig. 6. McCabe-Thiele plot for titanium(IV) extraction. $[\mathrm{Ti}(\mathrm{IV})]=0.03$ $\mathrm{mol} \mathrm{dm}-3,[\mathrm{HCl}]=7.5 \mathrm{~mol} \mathrm{dm}^{-3},[\mathrm{TOPO}]=0.044 \mathrm{~mol} \mathrm{dm}^{-3}$

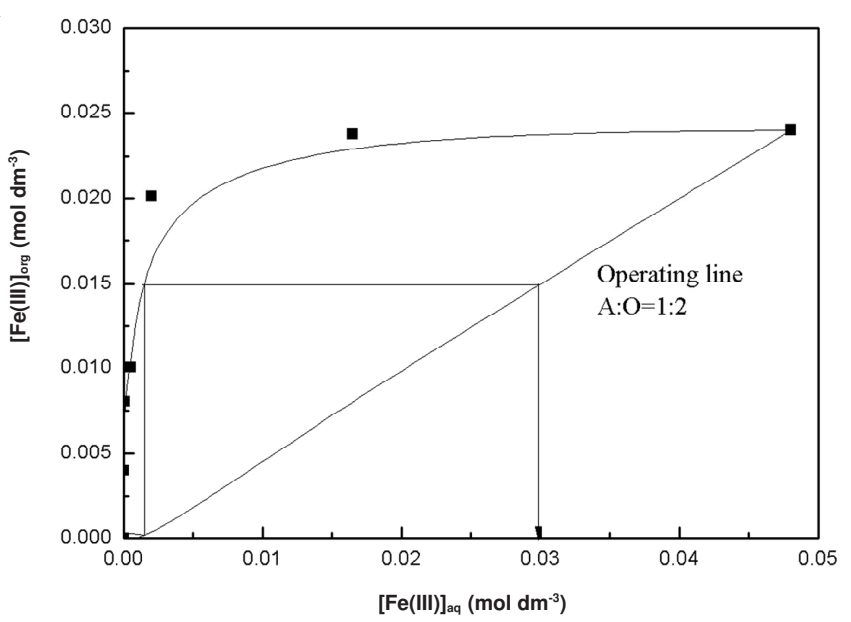

Fig. 7. McCabe-Thiele plot for iron(III) extraction. [iron(III) $]=0.03 \mathrm{~mol}$ $\mathrm{dm}^{-3},[\mathrm{HCl}]=7.5 \mathrm{~mol} \mathrm{dm}^{-3},[\mathrm{TOPO}]=0.044 \mathrm{~mol} \mathrm{dm}^{-3}$

Stripping and stripping isotherms: To develop a selective separation method for the recovery of titanium(IV) and iron(III) from the loaded organic phase, the stripping behaviour of these metal ions has been investigated using hydrochloric acid as the stripping agent. Fig. 8 shows that the stripping efficiency of titanium(IV) and iron(III) decreases with increased hydrochloric acid concentration. When using $6.0 \mathrm{~mol} \mathrm{dm}^{-3}$ 


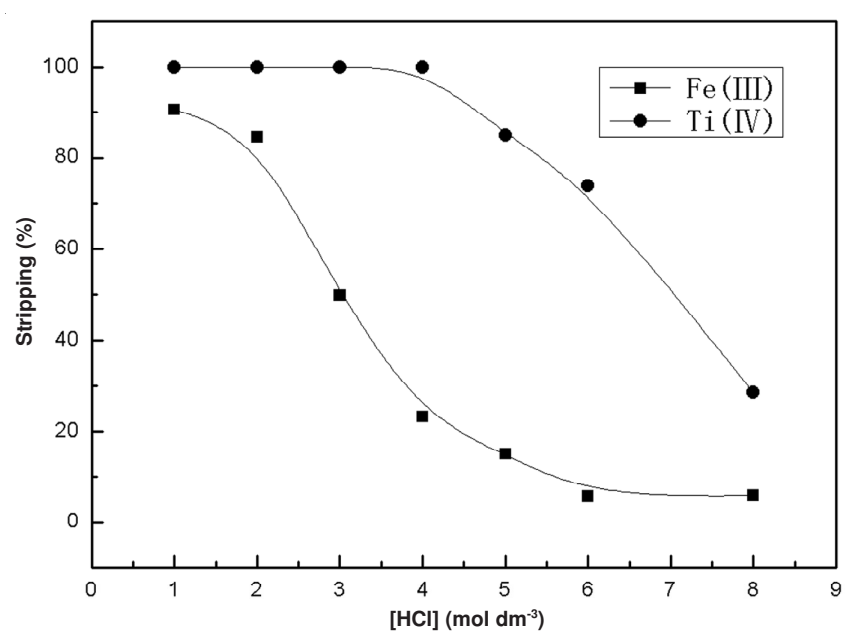

Fig. 8. Stripping behaviour of titanium(IV) and iron(III) from loaded TOPO phase using $\mathrm{HCl}$. Strip feed $=0.035 \mathrm{~mol} \mathrm{dm}^{-3}$ TOPO in kerosene containing $0.012 \mathrm{~mol} \mathrm{dm}^{-3} \mathrm{Ti}(\mathrm{IV})$ or $0.017 \mathrm{~mol} \mathrm{dm}^{-3} \mathrm{Fe}(\mathrm{III})$

hydrochloric acid as stripping agent, the stripping rate of titanium(IV) attains $74 \%$, with negligible stripping of iron(III). These results indicate that titanium(IV) and iron(III) can be selectively recovered from the loaded organic phase by controlling the acidity of the stripping agent. Thus titanium(IV) can be selectively separated using $6 \mathrm{~mol} \mathrm{dm}^{-3}$ hydrochloric acid, subsequently, iron(III) recovered using $0.5 \mathrm{~mol} \mathrm{dm}^{-3}$ hydrochloric acid.

Based on these results, a stripping isotherm for titanium(IV) was generated from a loaded organic phase consisting of 0.044 mol dm ${ }^{-3}$ TOPO in kerosene containing $0.03 \mathrm{~mol} \mathrm{dm}^{-3}$ titanium(IV) using $6 \mathrm{~mol} \mathrm{dm}^{-3}$ hydrochloric acid. A McCabeThiele plot (Fig. 9) of titanium(IV) stripping showed that quantitative stripping is possible in six stages with an 1:2 org:aq phase ratio. Similarly, a McCabe-Thiele plot (Fig. 10) of iron(III) stripping showed that quantitative stripping is possible in one or two stages using $0.5 \mathrm{~mol} \mathrm{dm}^{-3}$ hydrochloric acid at a 1:1 org:aq phase ratio.

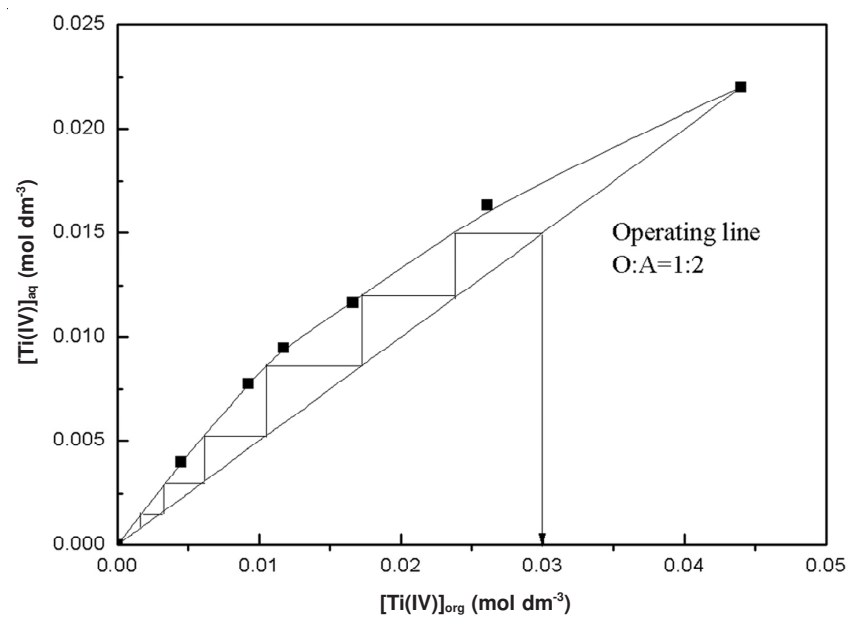

Fig. 9. McCabe-Thiele plot for titanium(IV) stripping. $[\text { Ti(IV) }]_{\text {org }}=0.03$ $\mathrm{mol} \mathrm{dm}{ }^{-3},[\mathrm{HCl}]=6.0 \mathrm{~mol} \mathrm{dm}^{-3}$

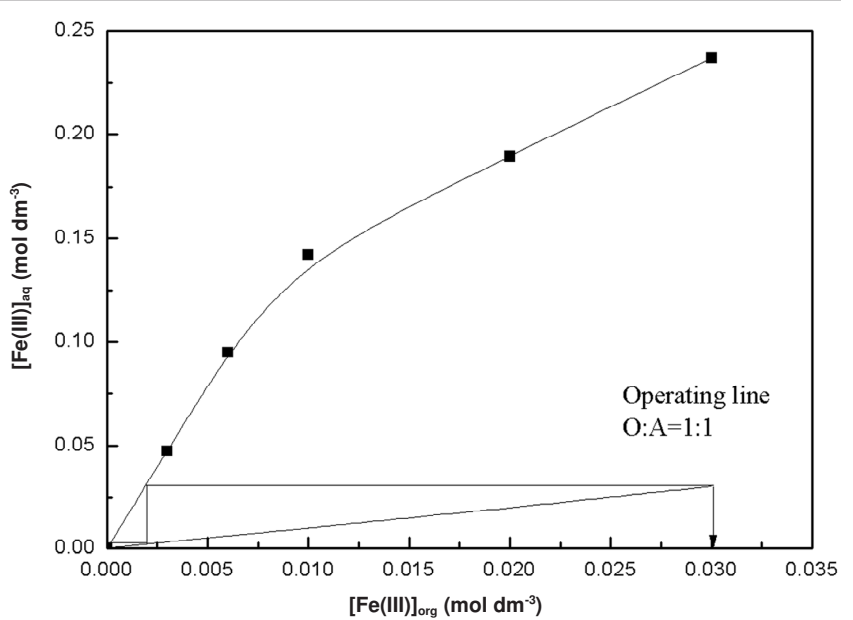

Fig. 10. McCabe-Thiele plot for iron(III) stripping. [Iron (III) $]_{\text {org }}=0.03 \mathrm{~mol}$ $\mathrm{dm}^{-3},[\mathrm{HCl}]=0.5 \mathrm{~mol} \mathrm{dm}{ }^{-3}$

\section{Conclusion}

The extraction behaviour of calcium(II), magnesium(II), aluminum(III), titanium(IV) and iron(III) from acidic chloride solutions has been investigated using TOPO in kerosene as an extractant. The results demonstrate that titanium(IV) and iron(III) are extracted into the organic phase, leaving behind the other metal ions in the raffinate. And that titanium(IV) and iron(III) can be selectively recovered from the loaded organic phase by controlling the acidity of the stripping agent. Thus the study clearly highlights that TOPO can be used as a potential extractant for the separation of titanium(IV) and iron(III) from titania chloride liquors. However, the practical utility of the current process requires further optimization of the various process parameters and also economic assessment of the process.

\section{ACKNOWLEDGEMENTS}

This work was financially supported by the National Natural Science Foundation of China (21076131).

\section{REFERENCES}

1. K.C. Sole, Hydrometallurgy, 51, 239 (1999).

2. K.C. Sole, Hydrometallurgy, 51, 263 (1999).

3. K.C. Sole, Hydrometallurgy, 51, 275 (1999).

4. P.N. Remya and M.L. Reddy, J. Chem. Technol., 79, 734 (2004).

5. M.L.P. Reddy and J. Saji, Miner. Process. Extr. Metal. Rev., 23, 199 (2002).

6. G.C. da Silva, J.W.S.D.d. Cunha, J. Dweck and J.C. Afonso, Miner. Eng., 21, 416 (2008).

7. J. Saji and M.L.P. Reddy, Sep. Sci. Technol., 38, 427 (2003).

8. J. Saji, K.S. John and M.L.P. Reddy, Solvent Extr. Ion Exch., 18, 877 (2000).

9. J. Saji and M.L.P. Reddy, Hydrometallurgy, 61, 81 (2001).

10. S. Seyfi and M. Abdi, Miner. Eng., 22, 116 (2009).

11. K.S. John, J. Saji, M.L.P. Reddy, T.R. Ramamohan and T.P. Rao, Hydrometallurgy, 51, 9 (1999).

12. H. Karimi and M. Gheadi, Asian J. Chem., 19, 4173 (2007).

13. K.M. Allal, D. Hauchard, M. Stambouli, D. Pareau and G. Durand, Hydrometallurgy, 45, 113 (1997).

14. S.I. El Dessouky, Y.A. El-Nadi, I.M. Ahmed, E.A. Saad and J.A. Daoud, Chem. Eng. Process, 47, 177 (2008). 